\title{
Erratum to: Ductile failure modeling
}

\author{
Ahmed Amine Benzerga • Jean-Baptiste Leblond • \\ Alan Needleman • Viggo Tvergaard
}

Published online: 17 October 2016

(C) Springer Science+Business Media Dordrecht 2016

\section{Erratum to: Int J Fract (2016) 201:29-80 DOI 10.1007/s10704-016-0142-6}

Equations (8) and (9) are wrong. The correct expressions are

$\dot{W}^{p}=(1-f) \bar{\sigma} \dot{\bar{\epsilon}}=\sigma: \mathbf{D}^{p}$

where $\bar{\sigma} \dot{\bar{\epsilon}}$ is the plastic dissipation rate per unit matrix material volume and

$\dot{\Lambda}=\frac{(1-f) \bar{\sigma} \dot{\bar{\epsilon}}}{\sigma:(\partial \Phi / \partial \sigma)}$

The online version of the original article can be found under doi:10.1007/s10704-016-0142-6.

\footnotetext{
A. A. Benzerga

Department of Aerospace Engineering, Texas A\&M

University, College Station, TX, USA

J.-B. Leblond

Institut Jean le Rond d'Alembert, Sorbonne Universités, Université Pierre et Marie Curie, Paris, France
A. Needleman ( $\square)$
Department of Materials Science and Engineering, Texas A\&M University, College Station, TX, USA
e-mail: needle@tamu.edu
V. Tvergaard
Department of Mechanical Engineering, The Technical
University of Denmark, Lyngby, Denmark 